\title{
Polyclonal Burkholderia cepacia Complex Outbreak in Peritoneal Dialysis Patients Caused by Contaminated Aqueous Chlorhexidine
}

\author{
Sally C.Y. Wong, ${ }^{1}$ Shuk-Ching Wong, Jonathan H.K. Chen, Rosana W.S. Poon, \\ Derek L.L. Hung, Kelvin H.Y. Chiu, Simon Y.C. So, Wing Shan Leung, Tak Mao Chan, \\ Desmond Y.H. Yap, Vivien W.M. Chuang, Kwok-Yung Yuen, ${ }^{2}$ Vincent C.C. Cheng ${ }^{2}$
}

Whether Burkholderia cepacia complex should be an objectionable organism in antiseptic solutions with acceptable total bacterial counts is controversial. By using nextgeneration sequencing, we documented a polyclonal $B$. cepacia complex outbreak affecting peritoneal dialysis patients in Hong Kong that was caused by contaminated chlorhexidine solutions. Epidemiologic investigations at a manufacturing site identified a semiautomated packaging machine as the probable source of contamination in some of the brands. Use of whole-genome sequencing differentiated the isolates into 3 brand-specific clonal types. Changes in exit site care recommendations, rapid recall of affected products, and tightening of regulatory control for chlorhexidine-containing skin antiseptics could prevent future similar outbreaks. Environmental opportunistic pathogens, including $B$. cepacia complex, might be included in regular surveillance as indicator organisms for monitoring environmental contamination.

Rurkholderia cepacia is the type species of the genus

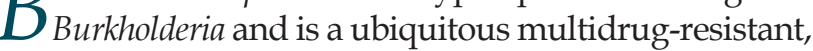
motile, non-glucose-fermenting, gram-negative organism found in water and soil (1). The B. cepacia complex (BCC) contains $\geq 17$ closely related species that require molecular methods for accurate differentiation (2). Previous typing methods, such as pulsed-field gel electrophoresis, restriction fragment-length polymorphism, or

Author affiliations: Queen Mary Hospital, Hong Kong, China (S.C.Y. Wong, S.-C. Wong, J.H.K. Chen, R.W.S. Poon,

D.L.L. Hung, K.H.Y. Chiu, S.Y.C. So, W.S. Leung,

Vincent C.C. Cheng); The University of Hong Kong, Hong Kong (T.M. Chan, D.Y.H. Yap, K.Y. Yuen); Hospital Authority, Hong Kong (V.W.M. Chuang)

DOI: https://doi.org/10.3201/eid2609.191746 multilocus sequence typing (MLST), are ineffective and only enable differentiation into genome variants.

$\mathrm{BCC}$ is a major pathogen among patients with cystic fibrosis and an opportunistic pathogen affecting patients with indwelling medical devices and immunosuppression (3). Although >50 BCC-related nosocomial outbreaks associated with contaminated antiseptics or medications have been described, none of the skin disinfectant-related outbreaks were documented by next-generation genome sequencing as the typing method. The exact mode of contamination of commercial antiseptics was often not found $(4,5)$. Implicated disinfectants and medications included intrinsically or extrinsically contaminated chlorhexidine (4-11), povidone-iodine $(12,13)$, benzalkonium chloride (14-16), intravenous fluids or drugs (17-20), sodium docusate $(21,22)$, eye drops (23), alcohol-free mouthwash, and nebulized salbutamol and albuterol (24-26).

There is a lack of consensus on whether B. cepacia should be considered an objectionable organism in nonsterile pharmaceutics according to guidelines for the United States and Europe (27-30). We report an outbreak involving $\geq 2$ clusters of BCC strains among peritoneal dialysis patients caused by multiple brands of contaminated, prepackaged, single-use, $0.05 \%$ aqueous chlorhexidine (aqCHX) solutions.

\section{Materials and Methods}

\section{Outbreak Investigation}

On September 6, 2019, we conducted an investigation at the Queen Mary Hospital Dialysis Unit in

${ }^{1}$ Current affiliation: Queen Elizabeth Hospital, Hong Kong, China.

${ }^{2}$ These senior authors contributed equally to this article. 
Hong Kong when a cluster of 4 dialysis patients had BCC isolated from their exit site. All 4 patients had recent-onset serous to bloody discharge from their exit site ( 3 peritoneal dialysis catheter exit sites and 1 hemodialysis catheter exit site). The hospital is a 1,700-bed university-affiliated tertiary referral center serving $\approx 270$ peritoneal dialysis and 110 hemodialysis patients. Noting the unusual number of BCC among renal patients, we performed case finding and established baseline incidence rate of BCC during January 1, 2014-September 9, 2019, by using a laboratory information system (software system that records, manages, and stores data for clinical laboratories).

For the outbreak investigation, we defined a case-patient as a peritoneal dialysis patient who had BCC isolated from clinical specimens during March 13, 2018-October 30, 2019. The medical records of case-patients were reviewed by the infection control team as described (31). Epidemiologic investigation at the renal unit was performed, and nursing staff were interviewed and observed for any changes in their patient care practice; patients and their relatives, if available, were interviewed about their exit site care procedures. Environmental surveillance was conducted as described in the next section. Active surveillance was initiated for all peritoneal dialysis patients; we collected exit site swab specimens to screen for additional BCC cases. Ethics approval was obtained from the institutional review board of the University of Hong Kong/Hospital Authority Hong Kong West Cluster.

\section{Environmental Surveillance}

Air, water, and environmental samples from the peritoneal dialysis unit, together with various antiseptics used for exit site care from our hospital and the community, were collected and microbiologically analyzed as described $(31,32)$ (Appendix, https:/ / wwwnc.cdc.gov/EID/article/26/9/19-1746-App1. pdf). In brief, we collected surface specimens by using premoistened, Polywipe sponge swabs (Medical Wire \& Equipment, https://www.mwe.co.uk). We sampled faucets and drains of sinks by using transport rayon swabs (Copan Diagnostics, https:/ / www.copanusa.com). We collected tap water (250 $\mathrm{mL}$ ) into labeled sterile bottles. We used an air sampler, SAS Super ISO 180 model 86834 (VWR International PBI Srl, https://it.vwr.com), to collect 1,000 liters of air onto MacConkey agar (CM 0507; Oxoid, http:/ / www.oxoid.com) containing $0.0005 \%$ crystal violet (Merck KGaA, https:/ / www.emdgroup.com) and $4 \mu \mathrm{g} / \mathrm{mL}$ gentamicin (CG-MAC). We collected in-use and unopened antiseptics in the hospital.
Unopened $0.05 \%$ aqCHX was also obtained from other (outside) stores.

Tap water was filtered through a $0.45-\mu \mathrm{m}$ membrane, which was then inoculated onto CG-MAC. Sponge swabs and transport rayon swabs were incubated in sterile selective brain heart infusion broth (CM1135; Oxoid) containing $4 \mu \mathrm{g} / \mathrm{mL}$ gentamicin, $15 \mu \mathrm{g} / \mathrm{mL}$ vancomycin, and $1 \mu \mathrm{g} / \mathrm{mL}$ amphotericin B (G3632, V2002, and A4888, respectively; SigmaAldrich, https://www.sigmaaldrich.com) at $37^{\circ} \mathrm{C}$ overnight before inoculation onto CG-MAC. All disinfectants and antiseptics were subjected to 1:10 dilution with neutralization broth (brain-heart infusion plus 2\% Tween 80 [P1754; Sigma-Aldrich], 0.3\% sodium thiosulphate pentahydrate [27910.260; VWR Chemicals, https://us.vwr.com], $0.4 \%$ potassium dihydrogen phosphate [26936.260; VWR Chemicals], and $0.5 \%$ lecithin). The suspension was left at room temperature for $5 \mathrm{~min}$, then $100 \mu \mathrm{L}$ of the suspension was spread onto blood agar (CM0331; Oxoid). Water and air samples were incubated at $37^{\circ} \mathrm{C}$ for 1 day, followed by room temperature for 5 days. Other specimens were incubated at $37^{\circ} \mathrm{C}$ for 5 days and examined daily for visible bacterial growth. Any bacterial growth was further speciated, and bacterial CFUs were also counted for air and antiseptic cultures.

\section{Clinical Specimens}

We processed all clinical specimens obtained before the outbreak investigation according to standard laboratory operating procedures. We performed active surveillance for BCC collected by swabbing catheter exit sites for all peritoneal dialysis patients. These swab specimens were inoculated onto CG-MAC for incubation at $37^{\circ} \mathrm{C}$ for 2 days. Patients with clinical symptoms suggestive of invasive catheter-related infection were investigated accordingly (e.g., peritoneal fluid or blood culture).

\section{Field Investigation at Brand B Manufacturing Site}

On September 19, 2019, a joint field investigation at brand B manufacturing site was conducted by a team of field epidemiologists, infection control professionals, and clinical microbiologists. The process of reconstitution, dilution, and packaging of 5\% chlorhexidine solution into individually packed $25-\mathrm{mL}$ volumes of $0.05 \%$ aqCHX was directly observed. Environmental samples and antiseptics were collected for microbiological investigations as described in the previous sections.

\section{Identification by Matrix-Assisted Laser Desorption/lonization Time-of-Flight Mass Spectrometry} We picked bacterial colonies from blood agar or CG-MAC for matrix-assisted laser desorption/ 
ionization time-of-flight (MALDI-TOF) mass spectrometry identification with bacterial colony protein extraction by using a direct transfer method. We measured mass spectra of isolates by using the MBT Smart Mass Spectrometer (Bruker Daltonik, https:/ / www.bruker.com) and the Bruker MBT Database 9.0 (8326 spectra). Scores $>2.0$ were considered as showing high-confidence identification and scores of 1.72.0 as showing low-confidence identification.

Whole-Genome Sequencing and Bioinformatic Analysis We further analyzed environmental and clinical BCC isolates by using the NovaSeq 6000 Sequencing System (Illumina Inc., https://www.illumina.com) at The University of Hong Kong Li Ka Shing Faculty of Medicine, Centre for PanorOmic Sciences, Genomics Core (Appendix). Two archived outbreak-unrelated BCC isolates were used as controls. We extracted MLST profiles from whole-genome assemblies by using BIGSdb, which is available on the BCC PubMLST website (33). We performed phylogenetic analysis according to single-nucleotide polymorphisms (SNPs) by using CSIPhylogeny version 1.4 with default settings (Appendix) (34). Results from CSIPhylogeny were subsequently imported into FigTree version 1.4.4 (http://tree.bio.ed.ac.uk) for visualizing the phylogenetic tree.

\section{Statistical Analysis}

We used the exact rate ratio test to compare exit site infection (ESI) rates between centers with and without routine chlorhexidine use. A $p$ value $<0.05$ was considered statistically significant. We applied the Holm-Bonferroni correction for multiple comparisons to control the familywise error rate at 0.05 . We used the $\mathrm{R}$ package rateratio.test (https://www.r-project. org) to perform calculations. We used an independent $t$-test to compare means of outbreak durations involving nonsterile and sterile sites. We used SPSS Statistics 20 (IBM, https:/ / www.ibm.com) to perform this analysis.

\section{Results}

\section{Epidemiologic Investigation}

On September 6, 2019, we launched an outbreak investigation when BCC was isolated from 3 peritoneal dialysis catheter exit sites and 1 hemodialysis catheter exit site for 4 patients ( 2 women and 2 men; age range $49-90$ years, median age 60.5 years). The exit site swab specimens were used for investigation of suspected ESI on September 4, 2019. Three patients had BCC isolated from previous exit site specimens,
1 from as early as September 24, 2018. The number of days from catheter insertion to first isolation of BCC ranged from 300 to 2,329 days (mean 1,084.5 days, median 854.5 days).

Retrospective case finding of BCC showed an increasing trend over time among nonduplicated dialysis patients since March 2018. During March 13, 2018-September 6, 2019, BCC was isolated from 53 renal patients, including 47 peritoneal dialysis catheter exit sites and 2 peritoneal fluid specimens (Table 1). The incidence rate of BCC isolated from peritoneal dialysis catheters during 2018-2019 was $>2$ SD from baseline (Figure 1), confirming an outbreak of BCC among peritoneal dialysis patients. Interviews with ward staff and observation of patient care practice found no recent changes or irregularity but showed that peritoneal dialysis patients purchased $0.05 \%$ aqCHX from community stores and used this solution for routine exit site care. Brands A and B were the commonest aqCHX bought by peritoneal dialysis patients because they were the most readily available brands in the community.

\section{Environmental Surveillance}

We collected 63 environmental and antiseptic specimens used in peritoneal dialysis catheter exit site care from the renal unit (Table 2). Different brands of aqCHX were purchased in the community (brands A-F) and collected in the hospital (brands G and $\mathrm{H})$. All 77 aqCHX collected in the hospital were culture negative, but 103 of the 104 community aqCHX showed bacterial growth (Table 2). Brand A of aqCHX had an average bacterial load of $3.6 \times 10^{5}$, and brand $\mathrm{B}$ had a value of $5.9 \times 10^{4} \mathrm{CFU} / \mathrm{mL}$. No BCC was isolated from environmental samples and other antiseptics collected from the renal unit.

\section{Clinical Specimens}

We collected peritoneal dialysis catheter exit site swab specimens from 275 patients for BCC surveillance. A total of $62(22.5 \%)$ patients were positive for BCC, 33.9\% (21/62) of whom had a genuine infection. A total of $29.0 \%(18 / 62)$ were among the 53 BCC-positive peritoneal dialysis patients identified from retrospective case finding.

\section{Field Investigation at Brand B Manufacturing Site}

We observed the entire process from dilution to packaging of aqCHX. In brief, $5 \%$ aqCHX was diluted with distilled water in the mixing compartment of a semiautomated packaging machine, which channeled and packed the diluted solution into 
Table 1. Specimen types and demographic characteristics for 53 renal dialysis patients from whom Burkholderia cepacia complex was isolated, Hong Kong, China, March 13, 2018-September 6, 2019*

\begin{tabular}{|c|c|c|c|}
\hline Characteristic & 2018,25 patients & 2019,28 patients & Total, 53 patients \\
\hline Specimen type & $\begin{array}{l}23 \text { PD catheter ES; } 1 \text { HD } \\
\text { catheter ES; } 1 \text { ES swab } \\
\text { specimen not otherwise } \\
\text { specified }\end{array}$ & $\begin{array}{l}23 \text { PD catheter ES; } 2 \\
\text { HD catheter ES; } 2 \\
\text { peritoneal fluid; } 1 \text { blood } \\
\text { culture from HD catheter }\end{array}$ & $\begin{array}{l}46 \text { PD catheter ES; } 3 \text { HD } \\
\text { catheter ES; } 2 \text { peritoneal } \\
\text { fluid; } 1 \text { blood culture from } \\
\text { HD catheter; } 1 \text { ES swab } \\
\text { specimen not otherwise } \\
\text { specified }\end{array}$ \\
\hline Age, y, mean (median, range) & $60.1(65,24-81)$ & $65.8(66,46-90)$ & $63.1(66,24-90)$ \\
\hline Sex ratio, F:M & $16: 9$ & $13: 15$ & $29: 24$ \\
\hline $\begin{array}{l}\text { Days from PD/HD catheter insertion until first } \\
\text { isolation of } B \text {. cepacia complex, mean (median, } \\
\text { range) }\end{array}$ & $1,192(648,58-2,349)$ & $1,140(769.5,70-6,098)$ & $1,163,(713,58-6,198)$ \\
\hline B. cepacia complex peritonitis & 1 & 4 & 5 \\
\hline Removal of PD catheter & 1 & $\begin{array}{l}3 \text { (2 caused by renal } \\
\text { transplant) }\end{array}$ & 4 \\
\hline \multicolumn{4}{|l|}{ Previous infections } \\
\hline ESI caused by other organisms & 8 & 7 & 15 \\
\hline Peritonitis caused by other organisms & 4 & 6 & 10 \\
\hline $\begin{array}{l}\text { Antimicrobial drug use } \leq 1 \mathrm{y} \text { before isolation of } B \text {. } \\
\text { cepacian complex }\end{array}$ & 19 & 26 & 45 \\
\hline No. deaths $\dagger$ & 2 & 2 & 4 \\
\hline
\end{tabular}

25-mL sachets (Figure 2). Samples of antiseptics were taken before and after each step, together with additional environmental samples from the site. BCC was found in 19 of 29 environmental samples and antiseptics collected, and 3 freshly packed antiseptics also yielded Achromobacter species (Table 2). BCC was first detected at a low level after chlorhexidine was diluted with distilled water in the semiautomated machine, then at high level in all subsequent packaged aqCHX, implying that the machine was the probable source of contamination. No BCC was found in the distilled water, air samples, or samples taken from measuring beaker, mixing rod, and unused package material.

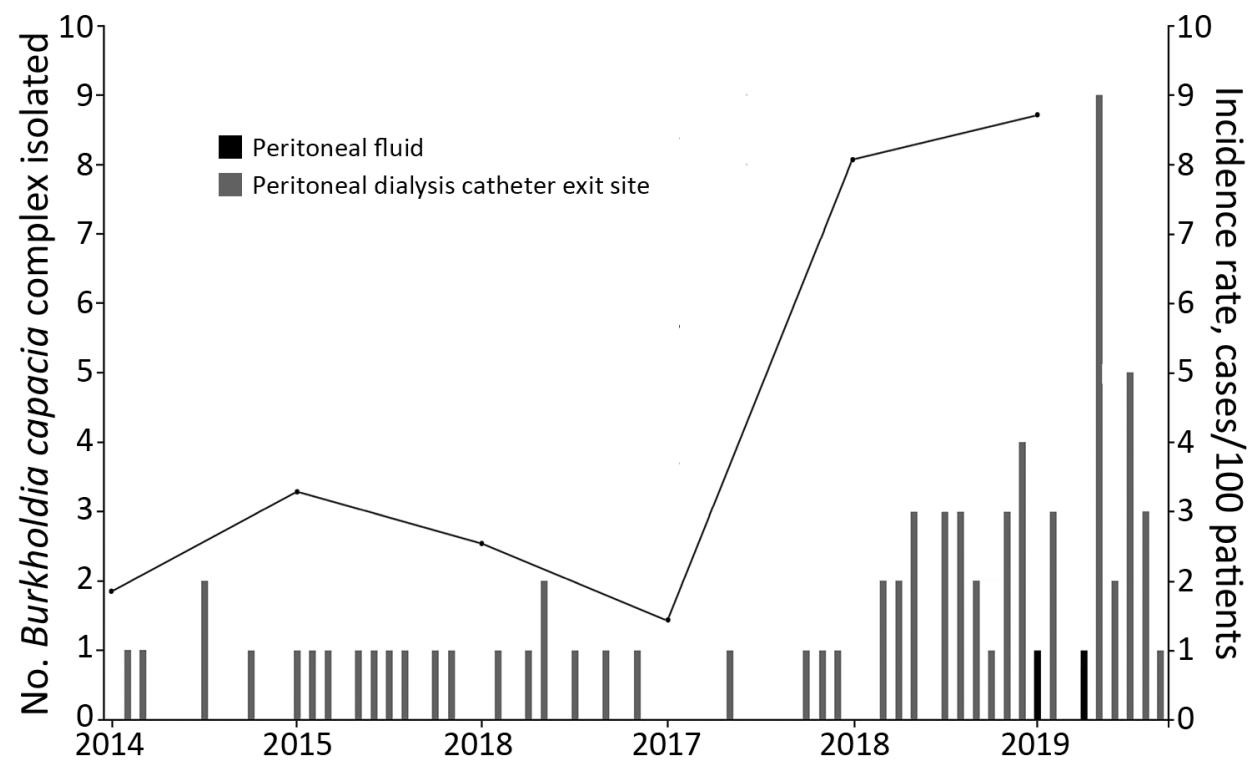

Identification by MALDI-TOF Mass Spectrometry

All isolates were identified correctly to the genus level and had scores $\geq 1.7$. Further species identification within the BCC was not possible.

Whole-Genome Sequencing and Bioinformatic Analysis A total of 80 isolates (52 patient isolates from active surveillance; 26 chlorhexidine-related isolates, including 5 isolates from the manufacturing site; and 2 outbreak-unrelated strains) were subjected to genome sequencing (Appendix Tables 1, 2). MLST analysis identified 2 predominant types. All BCC isolated from brands A, D, and E aqCHX (from the same company) were $B$. cenocepacia genomovar IIIA sequence 
Table 2. Environmental specimens collected and tested for investigation of Burkholderia cepacia complex outbreak in peritoneal dialysis unit, Hong Kong, China, March 13, 2018-September 6, 2019*

\begin{tabular}{|c|c|c|}
\hline Characteristic & $\begin{array}{l}\text { No. } \\
\text { specimens }\end{array}$ & $\begin{array}{l}\text { Culture result (mean, median, range), } \\
\qquad \mathrm{CFU/mL}\end{array}$ \\
\hline \multicolumn{3}{|l|}{ Peritoneal dialysis unit } \\
\hline \multicolumn{3}{|l|}{ Environment } \\
\hline Air samples & 2 & Negative for BCC \\
\hline Swab specimens from sink and faucet & 12 & \\
\hline Water samples from sink in ward & 10 & \\
\hline Soaps from dispensers next to patient sinks & 4 & \\
\hline Swab specimens from wound dressing trolleys & 3 & \\
\hline Blood pressure cuffs, gloves, and tissue paper & 6 (2 each) & \\
\hline Connection shield SysllK with povidone-iodine solution† & 3 & \\
\hline \multicolumn{3}{|l|}{ Exit site care agents } \\
\hline In-use povidone-iodine & 10 & Negative for BCC \\
\hline $\begin{array}{l}\text { Single-use prepackaged saline and sterile water } \\
\text { White wine vinegar }\end{array}$ & $\begin{array}{c}10 \text { (5 each) } \\
3\end{array}$ & \\
\hline \multicolumn{3}{|l|}{ Aqueous chlorhexidine } \\
\hline Brand A (outside hospital) & 51 & $\begin{array}{c}43 \text { with BCC only }\left(3.6 \times 10^{3}, 1.9 \times 10^{2}, 2.7-\right. \\
\left.7.6 \times 10^{4}\right) ; 4 \text { with Ralstonia species only } \\
(77,85,46-93) ; 4 \text { with BCC and Ralstonia } \\
\text { species }(120,120,94-130)\end{array}$ \\
\hline Brand B (outside hospital) & 45 & $\begin{array}{c}45 \text { with BCC }\left(5.9 \times 10^{4}, 4.6 \times 10^{4}, 2.9 \times\right. \\
\left.10^{4}-1.2 \times 10^{5}\right)\end{array}$ \\
\hline Brand C (outside hospital) & 4 & $\begin{array}{c}4 \text { with } \operatorname{BCC}\left(8.3 \times 10^{3}, 6.8 \times 10^{3}, 8 \times 10^{2}-\right. \\
\left.1.9 \times 10^{4}\right)\end{array}$ \\
\hline Brand D (outside hospital) & 2 & $\begin{array}{c}2 \text { with } \operatorname{BCC}\left(2.8 \times 10^{5}, 2.8 \times 10^{5}, 2.4-3.2 \times\right. \\
\left.10^{5}\right)\end{array}$ \\
\hline Brand E (outside hospital) & 1 & 1 with $\operatorname{BCC}\left(1.5 \times 10^{5}\right)$ \\
\hline Brand F (outside hospital) & 1 & Negative for BCC \\
\hline Brand G (from hospital) & 47 & Negative for BCC \\
\hline Brand H (from hospital) & 30 & Negative for BCC \\
\hline \multicolumn{3}{|l|}{ Brand $B$ manufacturing site } \\
\hline \multicolumn{3}{|l|}{ Environment } \\
\hline Air samples & 2 & Negative for $\mathrm{BCC}$ \\
\hline Plastic packaging & 1 & Negative for BCC \\
\hline Plastic container in preparation room & 1 & Negative for BCC \\
\hline Surface of fan in preparation room & 1 & Negative for BCC \\
\hline Surface of air conditioner in preparation room & 1 & Negative for BCC \\
\hline \multicolumn{3}{|l|}{ Specimens collected during dilution and packaging process } \\
\hline $5 \%$ chlorhexidine from original bottle & 1 & Negative for BCC \\
\hline Chlorhexidine in measuring beaker & 1 & Negative for BCC \\
\hline Distilled water & 1 & Negative for BCC \\
\hline $\begin{array}{l}\text { Diluted chlorhexidine in mixing compartment of semiautomated } \\
\text { packaging machine ([l] in Figure } 2 \text { ), before mixing with stirring rod }\end{array}$ & 1 & $\begin{array}{l}\text { BCC from enriched culture method with } \\
\text { overnight incubation in neutralization broth }\end{array}$ \\
\hline $\begin{array}{l}\text { Stirring rod surface swab specimen, before mixing diluted } \\
\text { chlorhexidine solution }\end{array}$ & 1 & Negative for BCC \\
\hline $\begin{array}{l}\text { Stirring rod surface swab specimen, after mixing diluted } \\
\text { chlorhexidine solution }\end{array}$ & 1 & $\begin{array}{l}\text { BCC from enriched culture method with } \\
\text { overnight incubation in neutralization broth }\end{array}$ \\
\hline $\begin{array}{l}\text { Diluted chlorhexidine in mixing bowl of packaging machine, after } \\
\text { mixing with stirring rod }\end{array}$ & 1 & $\begin{array}{l}\text { BCC from enriched culture method with } \\
\text { overnight incubation in neutralization broth }\end{array}$ \\
\hline Newly packed $25 \mathrm{~mL} 0.05 \%$ aqueous chlorhexidine & 16 & $\begin{array}{c}16 \ddagger \text { with BCC } 1.2 \times 10^{5}, 1.2 \times 10^{5}, 3.6 \times \\
\left.10^{4}-2.4 \times 10^{5}\right) ; 3 \text { with concurrent } \\
\text { Achromobacter species }\end{array}$ \\
\hline
\end{tabular}

type (ST) 1547, and all BCC isolated from brand B aqCHX and its manufacturing site were $B$. cepacia that had a novel ST (ST1693). The 2 BCC isolates from brand $\mathrm{C}$ were $\mathrm{B}$. cenocepacia that had another novel sequence (ST1694).

The phylogenetic tree based on core SNPs was consistent with the MLST results showing 2 predominant clusters with highly related strains within each cluster (Figure 3). Strains from clusters A corresponded to brand A (and D and E) aqCHX and cluster $\mathrm{B}$ corresponded to brand $\mathrm{B}$ aqCHX, except that 1 brand A isolate (BCAP168) was different from cluster A strains. Both strains in cluster $C$ corresponded to brand $\mathrm{C}$ aqCHX produced by a different company. A total of $47 / 52$ patient isolates were indistinguishable or closely related to those in cluster A. Forty of these 


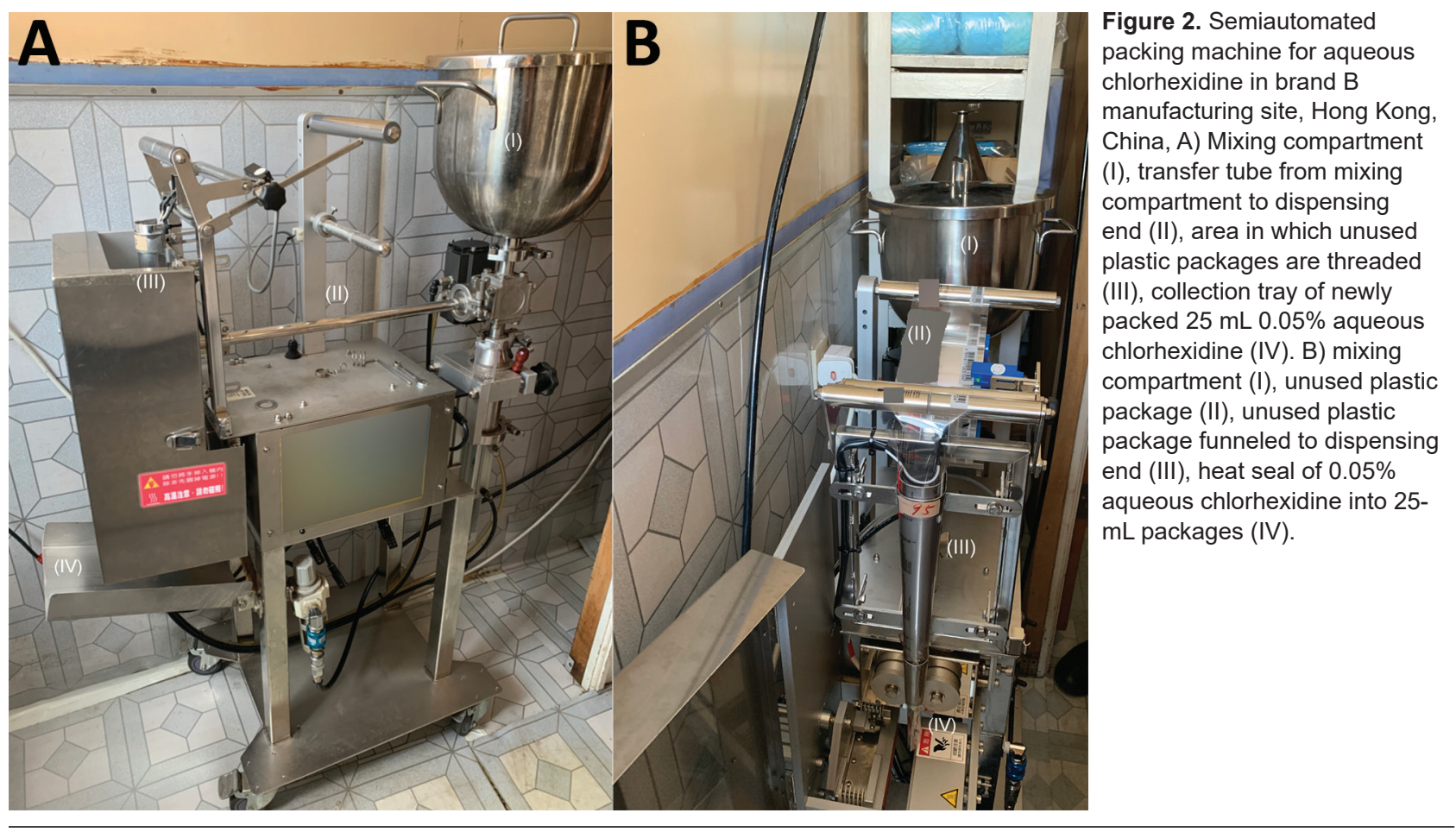

patients recalled using brand A for exit site care, 4 could not recall the brand used, and 3 reported using brand $\mathrm{B}$. Of the 5 patients with isolates closely related to those in cluster $\mathrm{B}, 2$ reported using brand $\mathrm{B}$ for exit site care, 2 reported using brand A, and 1 could not recall the brand used. The number of SNP differences in pairwise comparison of environment and patient isolates within cluster A was 0-165 and within cluster B was 0-32.

\section{Outbreak Control}

Upon reasonable suspicion of BCC contamination affecting prepacked aqCHX purchased in the community, the renal unit called all patients to stop such a practice and arranged alternative means of exit site disinfection. On September 17, 2019, the Hospital Authority and Centre for Health Protection (CHP), Department of Health, Hong Kong, were notified of the finding of BCC in prepackaged aqCHX. Further investigation by CHP identified 183 affected patients in public and private hospitals in Hong Kong (35). Several additional affected brands of aqCHX were identified and voluntarily recalled by the corresponding companies (36). We performed snapshot ESI surveillance between centers with routine and nonroutine chlorhexidine use by using data provided by the Hospital Authority; no major difference were found between the 2 practices (Table 3). Thus, sterile saline was recommended for routine exit site care in peritoneal dialysis patients instead of aqCHX.
On October 8, 2019, the Guidance Notes on Classification of Products as Pharmaceutical Product under the Pharmacy and Poisons Ordinance (Cap. 138) related to chlorhexidine was revised. Skin antiseptic products containing chlorhexidine are now classified as pharmaceutical products unless otherwise stated or under certain exceptions. This guidance took effect on July 8, 2020 (37).

\section{Discussion}

We report a polyclonal outbreak of BCC among peritoneal dialysis patients in our hospital that was caused by several contaminated brands of prepackaged aqCHX, which led to a territory-wide contact tracing that identified additional affected patients in other hospitals. Some observations can be made from this and previous BCC outbreaks. First, BCC outbreaks involving nonsterile sites were usually more prolonged; the mean outbreak duration was 85.4 days (median 66 days) when $\geq 50 \%$ of outbreak strains were isolated from sterile sites, compared with a mean of 245.9 days and a median of 199 days when $\geq 50 \%$ of BCC were isolated from nonsterile sites $(p=0.001)$ (Appendix Tables 3, 4). This finding might have occurred because BCC isolated from nonsterile sites might go unnoticed or were dismissed as sporadic, especially for patients with known risk factors, such as peritoneal dialysis catheters.

Also, the number of patients involved in an outbreak correlated with geographic distribution of the 
contaminated source(s). For example, 2 recent, large BCC outbreaks involving 162 and 138 patients were caused by intrinsically contaminated intravenous saline and liquid docusate $(17,21,22)$; both items were distributed to multiple states in the United States. From these and previous experiences (38), opportunistic environmental pathogens, such as BCC and nonanthrax Bacillus, might be used as indicator organisms for environmental contamination and be included as part of routine surveillance.

The use of whole-genome sequencing (WGS) provided high-resolution information for further analysis of this outbreak. First, it enabled accurate identification of BCC to species level and preliminary typing of bacterial strains through MLST. Phenotypic tests and MALDI-TOF mass spectrometry are inaccurate in speciation within BCC, and unlike previous BCC outbreaks, in which identical antibiogram profiles were found among outbreak-related BCC $(4,39)$, the antibiogram profiles among isolates from our patients were variable.

Although WGS is becoming increasingly used for outbreak investigations, the technology is not readily available in usual clinical microbiology laboratories and can be costly. Thus, alternative molecular typing

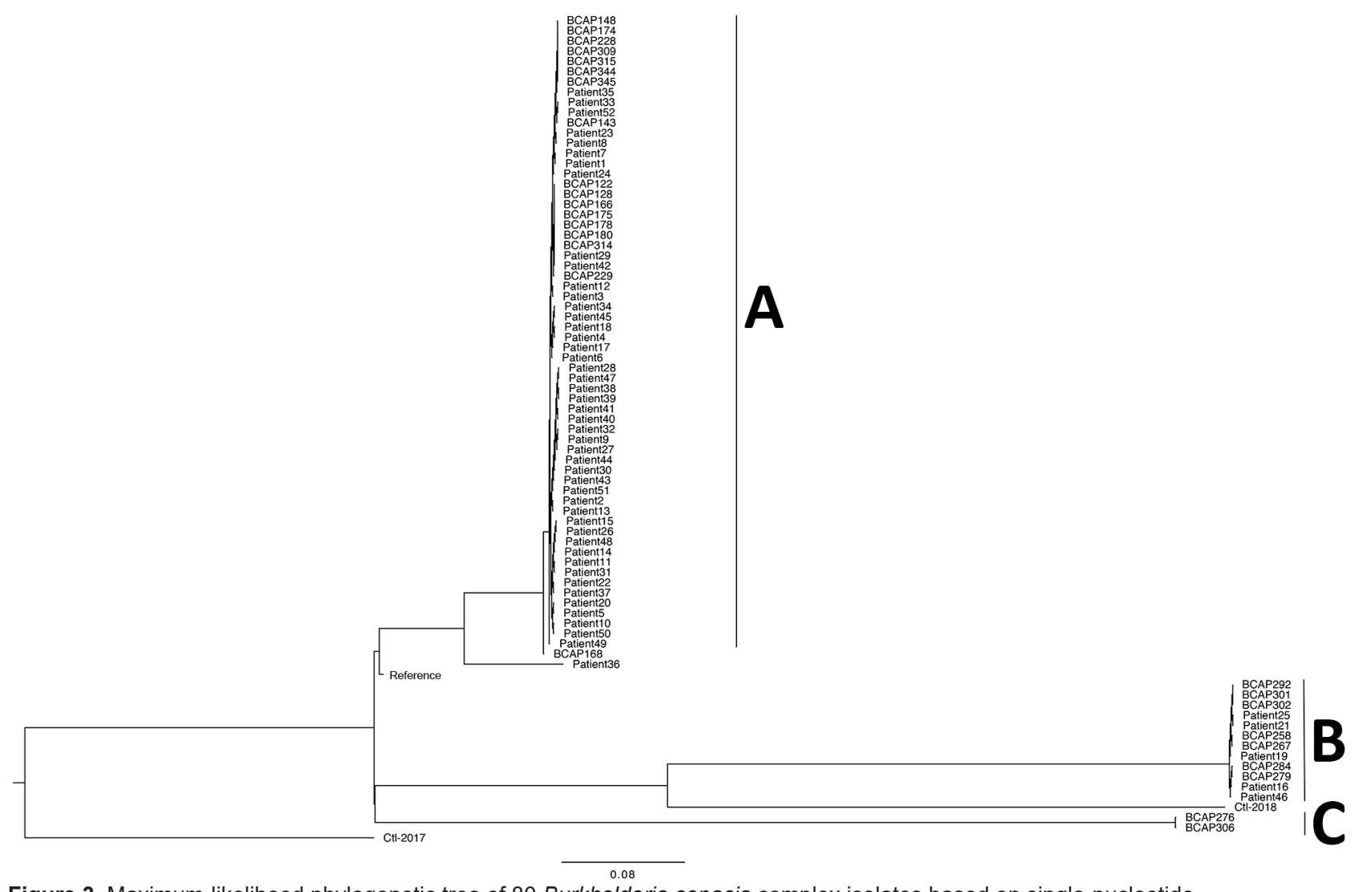

Figure 3. Maximum-likelihood phylogenetic tree of 80 Burkholderia cepacia complex isolates based on single-nucleotide polymorphisms, Hong Kong, China. A, B, and C indicate clusters. Scale bar indicates nucleotide substitutions per site. methods, such as MLST or restriction fragment length polymorphism, remains the first choice for nosocomial outbreak investigations because they often provide sufficient information for evaluation of smaller scale, more focused outbreaks. In addition, these methods are also helpful for preliminary evaluation of larger outbreaks. Nevertheless, we opted for WGS in our investigation because of anticipated large-scale involvement, and the need for high-resolution data for analysis to enable rapid enforcement of corrective measures at a regional level.

Phylogenetic analysis of the WGS data based on SNP differences unambiguously differentiated the outbreak BCC isolates into distinct clusters. Combined with epidemiologic findings and field investigation at brand $\mathrm{B}$ manufacturing site, we believe that the contamination of aqCHX most likely occurred at their corresponding manufacturing sites. First, brand A aqCHX was manufactured outside Hong Kong and had no direct geographic linkage with the brand B manufacturing site. Second, the 5\% chlorhexidine from the unopened bottle at the brand B manufacturing site did not show any growth of BCC, and presence of BCC was only detected in samples taken from the semiautomated machine, implying that the 
Table 3. Exit site infection rate of various microorganisms for patients in peritoneal dialysis centers in public hospitals, Hong Kong, China*

\begin{tabular}{|c|c|c|c|}
\hline \multirow[b]{2}{*}{$\begin{array}{l}\text { Microorganisms causing peritoneal dialysis } \\
\text { catheter exit site infections }\end{array}$} & \multicolumn{2}{|c|}{ No. infections/1,000 patient-years } & \multirow[b]{2}{*}{$\mathrm{p}$ value } \\
\hline & $\begin{array}{l}\text { Centers with routine } \mathrm{CHX} \text { use, } \\
\qquad \mathrm{n}=2,530 \text { patients }\end{array}$ & $\begin{array}{l}\text { Centers without routine } \mathrm{CHX} \text { use, } \\
\mathrm{n}=2,030 \text { patients }\end{array}$ & \\
\hline Coagulase-negative staphylococci & 95.25 & 72.41 & $0.0096 \dagger$ \\
\hline Diphtheroid bacilli & 19.37 & 31.53 & 0.0128 \\
\hline Streptococcus species & 74.70 & 65.02 & 0.2424 \\
\hline Methicillin-resistant Staphylococcus aureus & 49.41 & 57.64 & 0.2570 \\
\hline Methicillin-sensitive S. aureus & 62.45 & 70.44 & 0.3241 \\
\hline Enterobacterales $\ddagger$ & 95.65 & 86.70 & 0.3457 \\
\hline Candida species§ & 21.34 & 25.62 & 0.3990 \\
\hline \multicolumn{4}{|c|}{ 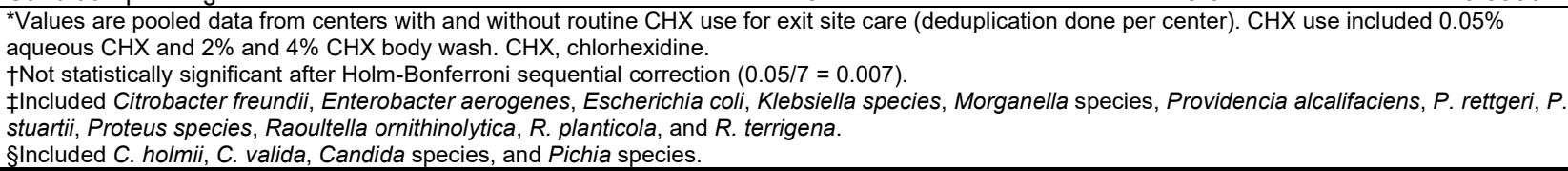 } \\
\hline
\end{tabular}

contamination had occurred during processing at the manufacturing site, rather than in the raw material. Third, the WGS analysis of clusters A and B, corresponding to brands A and B, were genetically distant. Although we cannot be certain of the exact time and duration of contamination, the retrospective case finding of B. cepacia isolated among our peritoneal dialysis patients during 2014-2019 showed a substantial increase only since March 2018, suggestive of a relatively recent event. We suspect that lapses in good manufacturing practices (GMPs) at various sites of chlorhexidine dilution led to bacterial contamination from the environment into the production line. BCC are ubiquitous in the environment and strains that have a MIC (>100 mg/L chlorhexidine) have been described, in which the minimum bactericidal concentration can be 3 times higher than the MIC (40).

The relative chlorhexidine resistance of $\mathrm{BCC}$ was believed to be caused by chromosomally encoded, resistant-nodulation-division efflux pumps, which up-regulate in the presence of sublethal concentrations of chlorhexidine (41). Thus, chlorhexidine led to the selection of a predominant BCC strain exhibiting high levels of resistance to chlorhexidine specific to each manufacturing site. In comparison, chlorhexidine has better antibacterial activities against staphylococci and Enterobacterales; thus, contamination of chlorhexidine by these organisms is rare, even at low chlorhexidine concentrations (Appendix Figure) (42).

The peritoneal dialysis catheter exit site care practice was revisited during this outbreak. Our local guideline stated that sterile saline and antiseptics, such as aqCHX, are acceptable (43), and the International Society for Peritoneal Dialysis 2017 guidelines stated that there is no evidence to suggest any antiseptics being superior in lowering the ESI rate (44). Some peritoneal dialysis centers have adopted routine use of chlorhexidine for ES care but a local snapshot audit on ESI rate supported the use of either sterile saline or aqCHX for exit site care.

Before the described outbreak, prepackaged aqCHX products were not considered to be pharmaceutical products in our locality because they were not labeled for use on broken skin nor had medicinal claims, and as such, these products were not registered with the Pharmacy and Poisons Board. The updated CHP guidance issued in response to this outbreak compels all chlorhexidine-containing skin antiseptic for human and animal use to be classified as pharmaceutical products unless otherwise stated, or except that these products are clearly labeled in English and Chinese for washing hands only (or equivalent); or chlorhexidine is used as a preservative or antimicrobial agent in cosmetic products, and necessitates that GMPs be observed, together with additional regulatory measures (45). Because terminal sterilization might inactivate or compromise the antimicrobial activity of particular antiseptics including, chlorhexidine, GMPs are relied upon to ensure the quality of the chlorhexidine produced, coupled with microbial testing of products to demonstrate their compliance with the limit laid out by the authorities $(27,28,46)$. We believe that antiseptics that are potentially used on wounds, compromised mucosal surfaces, exit sites or in immunocompromised patients should be subjected to regulations as pharmaceutical products to avoid future similar outbreaks.

This study had several limitations. First, the outbreak that we described was restricted to peritoneal dialysis patients. Non-peritoneal dialysis-related infections associated with contaminated aqCHX would not have been readily identified during initial case finding. Subsequent case finding based on exposure to contaminated aqCHX identified other affected groups of patients (e.g., persons with left ventricular- 
assisted devices). Also, BCC isolated from peritoneal dialysis patients before September 6, 2019, and older lots of aqCHX were not available. Thus, only BCC strains identified from active patient surveillance and recent lots of prepackaged aqCHX were included for WGS. Therefore, phylogenetic analysis of the environmental and clinical strains might only reflect recent transmissions. Nevertheless, isolates subjected to WGS were from 12 patients who were among the 53 patients identified by the initial retrospective case finding. All of these isolates were highly related to strains within cluster A. Finally, investigation of brand $C$ was not performed because there were no patient isolates within cluster $C$ and none of the peritoneal dialysis patients used this brand. Other affected brands of aqCHX were imported from outside Hong Kong. Therefore, field investigation at the manufacturing sites for these brands was also not possible. Nevertheless, all affected brands were recalled and will be subject to the new regulatory measures.

In conclusion, our investigations identified a polyclonal outbreak of BCC caused by contamination of multiple brands of commercial aqCHX. The findings illustrated that genome sequencing enabled high-resolution and accurate analysis of the outbreak strains, which facilitated identification of the probable cause or point of contamination. Timely actions and coordination between renal units, the Microbiology and Infection Control Services, Hospital Authority, and Department of Health ensured prompt control of the outbreak and amendment of peritoneal dialysis catheter exit site care practice guidelines, voluntary territory-wide recall of the contaminated aqCHX, and tightening of regulatory control of chlorhexidinecontaining skin antiseptics to prevent additional cases. Surveillance of environmental opportunistic pathogens, such as BCC, might enable these indicator organisms to be used to monitor environmental contamination for early detection of similar outbreaks.

\section{Acknowledgments}

We thank the Center for Health Protection, Department of Health, and S.K. Chuang for providing assistance in the investigation of the outbreak and comments that improved the manuscript; laboratory staff in the Department of Microbiology, Queen Mary Hospital, for providing additional effort in laboratory support during the outbreak investigation; and Herman Tse for providing advice on statistical analyses.

This study was supported in part by the Consultancy Service for Enhancing Laboratory Surveillance of Emerging Infectious Diseases of the Department of Health,
Hong Kong; and the Collaborative Innovation Center for Diagnosis and Treatment of Infectious Diseases, the Ministry of Education of China.

\section{About the Author}

Dr. Sally C.Y. Wong is an honorary assistant professor in the Department of Microbiology, The University of Hong Kong, Hong, Hong, China. Her research interests include Corynebacterium kroppenstedtii, multidrug-resistant organisms, and infection control and prevention.

\section{References}

1. Burkholder WH. Sour skin, a bacterial rot of onion bulbs. Phytopathology. 1950;40:115-7.

2. Devanga Ragupathi NK, Veeraraghavan B. Accurate identification and epidemiological characterization of Burkholderia cepacia complex: an update. Ann Clin Microbiol Antimicrob. 2019;18:7. https:/ / doi.org/10.1186/s12941-0190306-0

3. Jones AM, Dodd ME, Govan JR, Barcus V, Doherty CJ, Morris J, et al. Burkholderia cenocepacia and Burkholderia multivorans: influence on survival in cystic fibrosis. Thorax. 2004;59:948-51. https://doi.org/10.1136/thx.2003.017210

4. Ko S, An HS, Bang JH, Park SW. An outbreak of Burkholderia cepacia complex pseudobacteremia associated with intrinsically contaminated commercial $0.5 \%$ chlorhexidine solution. Am J Infect Control. 2015;43:266-8. https://doi.org/10.1016/j.ajic.2014.11.010

5. Song JE, Kwak YG, Um TH, Cho CR, Kim S, Park IS, et al. Outbreak of Burkholderia cepacia pseudobacteraemia caused by intrinsically contaminated commercial $0.5 \%$ chlorhexidine solution in neonatal intensive care units. J Hosp Infect. 2018;98:295-9. https:/ / doi.org/10.1016/ j.jhin.2017.09.012

6. Gleeson S, Mulroy E, Bryce E, Fox S, Taylor SL, Talreja H. Burkholderia cepacia: an outbreak in the peritoneal dialysis unit. Perit Dial Int. 2019;39:92-5. https://doi.org/10.3747/ pdi.2018.00095

7. Heo ST, Kim SJ, Jeong YG, Bae IG, Jin JS, Lee JC. Hospital outbreak of Burkholderia stabilis bacteraemia related to contaminated chlorhexidine in haematological malignancy patients with indwelling catheters. J Hosp Infect. 2008;70:241-5. https:// doi.org/10.1016/j.jhin.2008.07.019

8. Romero-Gómez MP, Quiles-Melero MI, Peña García P, Gutiérrez Altes A, García de Miguel MA, Jiménez C, et al. Outbreak of Burkholderia cepacia bacteremia caused by contaminated chlorhexidine in a hemodialysis unit. Infect Control Hosp Epidemiol. 2008;29:377-8. https://doi.org/10.1086/529032

9. Lee S, Han SW, Kim G, Song DY, Lee JC, Kwon KT. An outbreak of Burkholderia cenocepacia associated with contaminated chlorhexidine solutions prepared in the hospital. Am J Infect Control. 2013;41:e93-6. https:/ / doi.org/ 10.1016/j.ajic.2013.01.024

10. Montaño-Remacha C, Márquez-Cruz MD, Hidalgo-Guzmán P, Sánchez-Porto A, Téllez-Pérez FP. An outbreak of Burkholderia cepacia bacteremia in a hemodialysis unit, Cadiz, 2014 [in Spanish]. Enferm Infecc Microbiol Clin. 2015; 33:646-50. https://doi.org/10.1016/j.eimc.2015.02.013

11. Leong LE, Lagana D, Carter GP, Wang Q, Smith K, Stinear TP, et al. Burkholderia lata Infections from intrinsically contaminated chlorhexidine mouthwash, Australia, 2016. 
Emerg Infect Dis. 2018;24:2109-11. https:/ / doi.org/10.3201/ eid2411.171929

12. Berkelman RL, Lewin S, Allen JR, Anderson RL, Budnick LD, Shapiro S, et al. Pseudobacteremia attributed to contamination of povidone-iodine with Pseudomonas cepacia. Ann Intern Med. 1981;95:32-6. https:/ / doi.org/ 10.7326/0003-4819-95-1-32

13. Panlilio AL, Beck-Sague CM, Siegel JD, Anderson RL, Yetts SY, Clark NC, et al. Infections and pseudoinfections due to povidone-iodine solution contaminated with Pseudomonas cepacia. Clin Infect Dis. 1992;14:1078-83. https://doi.org/10.1093/clinids/14.5.1078

14. Frank MJ, Schaffner W. Contaminated aqueous benzalkonium chloride. An unnecessary hospital infection hazard. JAMA. 1976;236:2418-9. https:/ / doi.org/10.1001/ jama.1976.03270220038032

15. Lee CS, Lee HB, Cho YG, Park JH, Lee HS. Hospital-acquired Burkholderia cepacia infection related to contaminated benzalkonium chloride. J Hosp Infect. 2008;68:280-2. https://doi.org/10.1016/j.jhin.2008.01.002

16. Serikawa T, Kobayashi S, Tamura T, Uchiyama M, Tsukada H, Takakuwa K, et al. Pseudo outbreak of Burkholderia cepacia in vaginal cultures and intervention by hospital infection control team. J Hosp Infect. 2010;75:242-3. https:/ / doi.org/10.1016/j.jhin.2009.11.013

17. Brooks RB, Mitchell PK, Miller JR, Vasquez AM, Havlicek J, Lee H, et al.; Burkholderia cepacia Workgroup. Multistate outbreak of Burkholderia cepacia complex bloodstream infections after exposure to contaminated saline Flush syringes: United States, 2016-2017. Clin Infect Dis. 2019;69:445-9. https://doi.org/10.1093/cid/ciy910

18. Moreira BM, Leobons MB, Pellegrino FL, Santos M, Teixeira LM, de Andrade Marques E, et al. Ralstonia pickettii and Burkholderia cepacia complex bloodstream infections related to infusion of contaminated water for injection. J Hosp Infect. 2005;60:51-5. https:/ / doi.org/10.1016/ j.jhin.2004.09.036

19. Moehring RW, Lewis SS, Isaacs PJ, Schell WA, Thomann WR, Althaus MM, et al. Outbreak of bacteremia due to Burkholderia contaminans linked to intravenous fentanyl from an institutional compounding pharmacy. JAMA Intern Med. 2014;174:606-12. https:/ / doi.org/ 10.1001/jamainternmed.2013.13768

20. Pegues DA, Carson LA, Anderson RL, Norgard MJ, Argent TA, Jarvis WR, et al. Outbreak of Pseudomonas cepacia bacteremia in oncology patients. Clin Infect Dis. 1993;16:40711. https://doi.org/10.1093/clind/16.3.407

21. Marquez L, Jones KN, Whaley EM, Koy TH, Revell PA, Taylor RS, et al. An outbreak of Burkholderia cepacia complex infections associated with contaminated liquid docusate. Infect Control Hosp Epidemiol. 2017;38:567-73. https://doi.org/10.1017/ice.2017.11

22. Glowicz J, Crist M, Gould C, Moulton-Meissner H, Noble-Wang J, de Man TJ, et al.; B. cepacia Investigation Workgroup. A multistate investigation of health careassociated Burkholderia cepacia complex infections related to liquid docusate sodium contamination, JanuaryOctober 2016. Am J Infect Control. 2018;46:649-55. https://doi.org/10.1016/j.ajic.2017.11.018

23. Lalitha P, Das M, Purva PS, Karpagam R, Geetha M, Lakshmi Priya J, et al. Postoperative endophthalmitis due to Burkholderia cepacia complex from contaminated anaesthetic eye drops. Br J Ophthalmol. 2014;98:1498-502. https:/ / doi.org/10.1136/bjophthalmol-2013-304129

24. Memish ZA, Stephens G, Balkhy HH, Cunningham G, Francis C, Poff G; Saudi National Guard Infection Prevention and Control Group. Outbreak of Burkholderia cepacia bacteremia in immunocompetent children caused by contaminated nebulized sulbutamol in Saudi Arabia. Am J Infect Control. 2009;37:431-2. https:/ / doi.org/10.1016/ j.ajic.2006.10.002

25. Ghazal SS, Al-Mudaimeegh K, Al Fakihi EM, Asery AT. Outbreak of Burkholderia cepacia bacteremia in immunocompetent children caused by contaminated nebulized sulbutamol in Saudi Arabia. Am J Infect Control. 2006;34:394-8. https:// doi.org/10.1016/j.ajic.2006.03.003

26. Balkhy $\mathrm{HH}$, Cunningham $\mathrm{G}$, Francis $\mathrm{C}$, Almuneef MA, Stevens G, Akkad N, et al. A national guard outbreak of Burkholderia cepacia infection and colonization secondary to intrinsic contamination of albuterol nebulization solution. Am J Infect Control. 2005;33:182-8. https:/ / doi.org/ 10.1016/j.ajic.2005.01.001

27. Council of Europe. European pharmacopoeia. 9th ed. Strasbourg (France): The Council; 2016.

28. United States Pharmacopeial Convention. United States Pharmacopeia US. USP $<60>$ microbiological examination of nonsterile roduct. Tests for Burkholderia cepacia complex. North Bethesda, Maryland, December 1, 2019 [cited 2020 May10]. https://www.pharmawebinars.com/usp-60-testsfor-burkholderia-cepacia-complex

29. Scott S. What is an "objectionable organism"? American Pharmaceutical Review, October 12, 2012 [cited 2019 Nov 16]. https:/ / www.americanpharmaceuticalreview.com/ Featured-Articles/122201-What-is-an-ObjectionableOrganism-Objectionable-Organisms-The-ShiftingPerspective/

30. Elder D. Objectionable organisms in non-sterile medicinal products. European Pharmaceutical Review, January 4, 2018 [cited 2019 Nov 16] https://www.europeanpharmaceutical review.com/article/71150/objectionable-organismsnon-sterile-medicinal-products/

31. Cheng VC, Chen JH, Wong S, Leung SS, So SY, Lung DC, et al. Hospital outbreak of pulmonary and cutaneous zygomycosis due to contaminated linen items from substandard laundry. Clin Infect Dis. 2016;62:714-21. https://doi.org/10.1093/cid/civ1006

32. Cheng VC, Chan JF, Ngan AH, To KK, Leung SY, Tsoi HW, et al. Outbreak of intestinal infection due to Rhizopus microsporus. J Clin Microbiol. 2009;47:2834-43. https://doi.org/10.1128/JCM.00908-09

33. Jolley KA, Bray JE, Maiden MC. Open-access bacterial population genomics: BIGSdb software, the PubMLST.org website and their applications. Wellcome Open Res. 2018;3:124. https://doi.org/10.12688/wellcomeopenres.14826.1

34. Kaas RS, Leekitcharoenphon P, Aarestrup FM, Lund O. Solving the problem of comparing whole bacterial genomes across different sequencing platforms. PLoS One. 2014;9:e104984. https://doi.org/10.1371/ journal.pone.0104984

35. Centre for Health Protection. Update on Burkholderia cepacia complex infection (with photos). Department of Health, Hong Kong Special Administrative Region, October 4, 2019 [cited 2019 Nov 27]. https:// www.info.gov.hk/gia/ general/201910/04/P2019100400763.htm

36. Centre for Health Protection. Further recall of antiseptic products (with photos). Department of Health, Hong Kong Special Administrative Region, September 30, 2019 [cited 2019 Nov 23]. https:/ / www.info.gov.hk/gia/ general/201909/30/P2019093000732.htm

37. Department of Health, Drug Office, Drug Evaluation and Registration and Import/Export Control Division, Drug office. Guidance notes on classification of products as 
pharmaceutical products under the Pharmacy and Poisons Ordinance (Cap. 138). Department of Health, Hong Kong Special Administrative Region, October 8, 2019 [cited 2019 Nov 23]. https://www.drugoffice.gov.hk/eps/do/en/doc/ guidelines_forms/Guide_on_PRClass.pdf

38. Cheng VC, Chen JH, Leung SS, So SY, Wong S, Wong SC, et al. Seasonal outbreak of Bacillus bacteremia associated with contaminated linen in Hong Kong. Clin Infect Dis. 2017;64(suppl 2):S91-S7.

39. Paul LM, Hegde A, Pai T, Shetty S, Baliga S, Shenoy S. An outbreak of Burkholderia cepacia bacteremia in a neonatal intensive care unit. Indian J Pediatr. 2016;83:285-8. https://doi.org/10.1007/s12098-015-1855-7

40. Rose H, Baldwin A, Dowson CG, Mahenthiralingam E. Biocide susceptibility of the Burkholderia cepacia complex. J Antimicrob Chemother. 2009;63:502-10. https://doi.org/ 10.1093/jac/dkn540

41. Coenye T, Van Acker H, Peeters E, Sass A, Buroni S, Riccardi G, et al. Molecular mechanisms of chlorhexidine tolerance in Burkholderia cenocepacia biofilms. Antimicrob Agents Chemother. 2011;55:1912-9. https://doi.org/10.1128/ AAC.01571-10

42. Al-Adham I, Haddadin R, Collier P. Types of microbicidal and microstatic agents. In: Fraise AP, Maillard J-Y, Sattar SA, editors. Russell, Hugo and Ayliffe's: principles and practice of disinfection, preservation and sterilization, 5th ed. New York: Wiley-Blackwell Publishing; 2012. p. 18-20.

43. Infection Control Branch, Center for Health Protection and Central Renal Committee. Infection control guidelines on nephrology services in Hong Kong. Department of Health and Hospital Authority, Hong Kong Special Administrative Region, 3rd ed (version 3.1), 2018 [cited 2019 Sep 30]. https://www.chp.gov.hk/files/pdf/ic_gu_nephrology_ services_in_hk.pdf

44. Szeto CC, Li PK, Johnson DW, Bernardini J, Dong J, Figueiredo AE, et al. ISPD Catheter-related infection recommendations: 2017 update. Perit Dial Int. 2017;37:14154. https://doi.org/10.3747/pdi.2016.00120

45. Cap. 138 Pharmacy and Poisons Ordinance. 1970 Jan 1, L.N. 186 of 1969, amended 2015 [cited 2019 Sep 30]. https://www.elegislation.gov.hk/hk/cap138

46. Medical Solution Division. White paper: quality of 3M Canada skin antiseptic drug products. 3M Canada, June 2018 [cited 2019 Sep 30]. https:/ / multimedia.3m.com/mws/media/1455409O/ white-paper-quality-of-3m-canada-drug-products.pdf

Address for correspondence: Vincent C.C. Cheng, Department of Microbiology, Queen Mary Hospital, Hong Kong, China; email: vcccheng@hku.hk

\section{EID Podcast \\ TB in Internationally Displaced Children in Texas}

Internationally displaced children often face a barrage of conditionssuch as poor sanitation, nutrition, and access to healthcare-that increase their risk for disease. Upon the children's arrival in the United States, medical examinations can help uncover infectious diseases such as tuberculosis, which can remain latent for years before progressing into its more serious, contagious state. As testing methods improve, researchers are learning how tuberculosis rates can be complicated.

In this EID podcast, Dr. Gabriella Lamb, an assistant in medicine at Boston Children's Hospital, discusses TB testing in internationally displaced children in Texas. 